Estudios Constitucionales, Año 13, No 1, 2015, pp. 417-428.

ISSN 07180195

Centro de Estudios Constitucionales de Chile Universidad de Talca

"Reflexiones sobre el derecho a la propiedad colectiva indígena. Comentario del Informe de Fondo No 125/12 de la Comisión Interamericana de Derechos Humanos en el caso de los Pueblos indígenas

Kuna de Madungandí y Emberá de Bayano y sus miembros con Panamá"

Jaime Gajardo Falcón

\title{
REFLEXIONES SOBRE EL DERECHO A LA PROPIEDAD COLECTIVA INDÍGENA. COMENTARIO DEL INFORME DE FONDO No 125/12 DE LA COMISIÓN INTERAMERICANA DE DERECHOS HUMANOS EN EL CASO DE LOS PUEBLOS INDÍGENAS KUNA DE MADUNGANDÍ Y EMBERÁ DE BAYANO Y SUS MIEMBROS CON PANAMÁ*
}

\author{
REFLECTIONS ABOUT INDIGENOUS RIGHTS TO THE RIGHT TO PROPERTY. \\ COMmentary on Report No 125/12 OF the INTER-AMERICAN \\ COMmission on Human Rights in the CASE OF INDigenOUS PEOPLES \\ Embera and Kuna of Bayano Madungandí and \\ its members V. Panama
}

Jaime Gajardo FALCón ${ }^{* *}$ Universidad Autónoma de Madrid-España gajardofalcon@gmail.com

RESUMEN: En el presente trabajo analizaré y reflexionaré sobre las nuevas perspectivas que se abren en la configuración del derecho a la propiedad colectiva indigena y visualizaré los desafios que enfrentará la Corte Interamericana de Derechos Humanos en el conocimiento del caso de los Pueblos Indigenas Kuna de Madungandí y Emberá de Bayano y sus miembros con Panamá. Para lo anterior, luego de una breve introducción a los hechos del caso, colocaré en el contexto de la jurisprudencia de la Corte Interamericana de Derechos Humanos el informe de fondo en análisis y desde abí revisaré, críticamente, los aspectos "novedosos" que incorpora el caso para el Sistema Interamericano de Derechos Humanos en lo relativo al derecho de propiedad colectiva indigena.

ABSTRACT: The article focuses on the new perspectives about indigenous rights to the right to property and the challenges that will have the Inter-American Court of Human Rights in the case of Indigenous Peoples Kuna and Embera de Bayano Madungandi and its members with Panama. For this, after a brief introduction to the facts of the case, I will place the Report in the context of the

\footnotetext{
* Trabajo recibido el 29 de septiembre de 2014 y aprobado el 18 de marzo de 2015.

** Abogado, Licenciado en Ciencias Jurídicas y Sociales, Universidad de Chile. Magíster en Derecho, con mención en Derecho Público, Universidad de Chile. Máster en Gobernanza y Derechos Humanos, Universidad Autónoma de Madrid. Máster en Derecho Constitucional, Centro de Estudios Políticos y Constitucionales (España). Doctorando en Derecho y Ciencia Política, Universidad Autónoma de Madrid. Actualmente, se desempeña como Personal Investigador en Formación en la Universidad Autónoma de Madrid y es becario Chile (CONICYT) para estudios doctorales en el extranjero.
} 
Inter-American Court of Human Rights case law and from there I will review-critically- the "new" aspects that incorporate the case for the Inter-American System of Human Rights, regarding indigenous rights to the right to property.

PALABRAS CLAVES: Derechos humanos de los pueblos indígenas, propiedad colectiva indígena, Comisión Interamericana de Derechos Humanos, Corte Interamericana de Derechos Humanos.

KEY WORDS: Human Rights of indigenous people, indigenous rights to the right to property, InterAmerican Commission on Human Rights, Inter-American Court of Human Rights.

\section{INTRODUCCIÓN A LOS HECHOS Y CONTROVERSIAS \\ JURÍDICAS DEL CASO}

Recientemente, el 26 de febrero de 2013, la Comisión Interamericana de Derechos Humanos (en adelante "CIDH") ha remitido el caso No 12.354 respecto a la República de Panamá para conocimiento de la Corte Interamericana de Derechos Humanos (en adelante "Corte IDH"), debido a que la CIDH consideró que el Estado no cumplió con las recomendaciones contenidas en su Informe de Fondo, objeto del presente comentario, sobre el caso ${ }^{1}$.

El caso se originó el 11 de mayo de 2000 cuando la CIDH recibió una petición presentada por diversas organizaciones (los peticionarios) ${ }^{2}$, en favor de los pueblos indígenas Kuna de Madungandí y Emberá de Bayano y sus miembros, en contra de la República de Panamá, alegando que, a raíz de la construcción de la Represa Hidroeléctrica del Bayano entre los años 1972 y 1976, los pueblos indígenas fueron obligados a abandonar su territorio ancestral, el cual fue inundado con el embalse de la represa. Debido a lo anterior, las presuntas víctimas se reubicaron -obligadamente- en las nuevas tierras ofrecidas por el Estado (como de mejor calidad y cantidad), y aceptaron las indemnizaciones económicas que serían pagadas a cambio de la destrucción e inundación de su territorio ancestral. Sin embargo, los compromisos Estatales no fueron cumplidos, ya que las indemnizaciones no se pagaron en su totalidad y las tierras otorgadas no cumplieron con las características ofrecidas ${ }^{3}$.

1 Véase: Comisión Interamericana de Derechos Humanos (2013).

2 Los peticionarios son: 1) International Human Rights Law Clinic of the Washington College of Law; 2) el Centro de Asistencia Legal Popular (CEALP); 3) la Asociación Napguana; 4) Emily Yozell. Véase: Comisión Interamericana de Derechos Humanos (2012), párr. 1.

3 Específicamente, en cuanto al pueblo indígena Kuna de Madungandí, afirmaron que si bien el Estado reconoció formalmente en 1996 su derecho a la propiedad colectiva sobre las tierras que habitan, no ha cumplido con brindar protección efectiva frente a la constante invasión por parte de terceros no indígenas. Respecto al pueblo indígena Emberá del Bayano, sostuvieron que el Estado no ha cumplido a la fecha con 
Por su parte, el Estado sostuvo que no ha violado los derechos humanos de las presuntas víctimas, puesto que la construcción de la represa hidroeléctrica estuvo precedida por estudios técnicos para reducir su impacto negativo, y la realización de acuerdos con los pueblos indígenas Kuna y Emberá sobre su reubicación, otorgamiento de nuevas tierras y pago de indemnizaciones por las pérdidas ocasionadas 4 .

Delimitando la controversia jurídica del caso, la CIDH entiende que lo que está en discusión no es el derecho de propiedad de estos pueblos indígenas sobre los territorios que ocupan, sino la entrega de un título jurídico, en el caso de las comunidades del pueblo Emberá, así como la delimitación, demarcación y protección efectiva de los mismos, principalmente frente a terceros ocupantes, no correspondiéndole a la CIDH determinar los derechos de los habitantes no indígenas del área que no son parte del presente proceso, ni pronunciarse sobre el modo concreto en que debe llevarse a cabo el proceso de desalojo y reubicación de las personas no indígenas que permanecen en la zona ${ }^{5}$.

En lo relativo a la competencia ratione temporis, a pesar de que la CIDH ha dado por probado un conjunto de hechos ocurridos con anterioridad al 8 de mayo de 1978, fecha en que Panamá ratificó la Convención Americana sobre Derechos Humanos (en adelante "CADH"), los cuales se refieren principalmente al despojo e inundación de los territorios ancestrales de las presuntas víctimas, considera que si bien tales hechos se produjeron antes de la ratificación de la $\mathrm{CADH}$ por parte del Estado, las obligaciones a las que dieron lugar consistentes en el pago de indemnizaciones económicas y el reconocimiento de derechos sobre las tierras otorgadas, persisten aún después de esa fecha y han sido complementadas por actos estatales posteriores a los que se ha hecho referencia, así como por compromisos internacionales asumidos por el Estado ${ }^{6}$.

titular, delimitar y demarcar el territorio que ocupan, sino que, por el contrario, ha otorgado títulos de propiedad a terceras personas y ha permitido su apropiación ilegal por parte de campesinos. Véase: Ídem, párr. 2.

4 Véase: Ídem, párr. 3.

5 Ídem, párrs. 188-189.

${ }^{6}$ En el requisito ratione temporis la Corte IDH debe analizar el momento en que se produce la vulneración de los Derechos Humanos protegidos por la CADH, la que debe haber ocurrido con posterioridad a que la $\mathrm{CADH}$ haya entrado en vigor para el Estado denunciado y que es parte del sistema. La fuente normativa de dicho requisito es el artículo 28 de la CADH. Al respecto, Cecilia Medina y Claudio Nash señalan que "(...) en el sistema interamericano de protección de los derechos humanos, los Estados no pueden reclamar frente a la Comisión que a su respecto no existe obligación alguna de respetar y garantizar los derechos humanos antes 
Así, el caso se centra en la falta de cumplimiento de las obligaciones señaladas y en la falta de respuesta estatal ante las afectaciones al territorio indígena posteriores a los acuerdos y reconocimientos iniciales ${ }^{7}$.

\section{El CASO EN El CONTEXTO DE LA JURISPRUdenCiA DE LA CORTE IDH \\ Y SUS ASPECTOS NOVEDOSOS}

En el Informe en análisis se refuerzan los aspectos centrales de lo que ha significado el derecho de propiedad colectiva indígena en la jurisprudencia de la Corte $\mathrm{IDH}^{8}$. En ese sentido, se hace hincapié en su carácter colectivo ${ }^{9}$, en la

de la entrada en vigencia de la Convención Americana, ya que todos los Estados miembros de la OEA estaban sujetos, antes de la Convención, y respecto de ciertos derechos hasta ahora, a las normas de la Declaración Americana y la Comisión es competente para controlar su cumplimiento". Véase: Medina y NaSH (2011), p. 32. Asimismo, la CIDH se ha pronunciado al respecto, señalando que: "la Comisión no comparte la posible implicación del argumento de inadmisibilidad ratione temporis, según el cual los Estados miembros de la Organización contraen obligaciones de respetar los derechos humanos solo a partir de la ratificación de la Convención. Dicha premisa parecería sugerir que antes de la ratificación de la Convención, los Estados miembros no tenían obligación internacional alguna respecto de los derechos humanos y, concretamente, que esta Comisión no tiene competencia para recibir otras denuncias que las del texto Convencional", véase: Comisión Interamericana de Derechos Humanos (1990), p. 75. Sin embargo, la Corte IDH en el caso Grande con Argentina (2011), señaló que: "Argentina reconoció la competencia contenciosa de la Corte Interamericana el 5 de septiembre de 1984 y en su declaración interpretativa indicó que el Tribunal tendría competencia respecto de "hechos acaecidos con posterioridad a la ratificación" de la Convención Americana, efectuada en esa misma fecha. Con base en lo anterior y en el principio de irretroactividad, la Corte en principio no puede ejercer su competencia contenciosa para aplicar la Convención y declarar una violación a sus normas cuando los hechos alegados o la conducta del Estado que pudieran implicar su responsabilidad internacional son anteriores a dicho reconocimiento de la competencia”, véase: CORTE Interamericana de Derechos Humanos, 31 de agosto de 2011, párr. 37. En el caso Radilla con México, la Corte IDH estableció una excepción al principio de ratione temporis, cuando la violación a la CADH se sigue realizando de forma continua, a pesar de que el hecho basal sea anterior a la ratificación por parte del Estado de la CADH. Justamente, esta idea es la que sostendrá la CIDH en el presente caso ante la Corte IDH. Ello es interesante, ya que el caso Radilla es sobre desaparición forzada, por lo que veremos si la Corte IDH extiende dicha interpretación a un caso de conflicto indígena que posee una naturaleza muy diferente. Al respecto, véase: Corte Interamericana de Derechos Humanos, 23 de noviembre de 2009, párrs. 44-51.

7 Véase: Comisión Interamericana de Derechos Humanos (2012), párr. 191.

8 Ídem, párrs. 192-195. Asimismo, para un extracto de las sentencias de la Corte IDH relevantes al respecto, véase: Espejo y LeIva (2012), pp. 549-562. Para un estudio amplio al respecto, véase: Comisión Interamericana de Derechos Humanos (2009). Asimismo, véase: Nash (2004), pp. 29-43. Para un estudio crítico de las consecuencias prácticas de la jurisprudencia de la Corte IDH en materia de propiedad indígena, véase: АNTOKOWIAK (2014), pp. 113-187.

9 Véase: Comisión Interamericana de Derechos Humanos (2012), párr. 195. Asimismo, para un análisis teórico de los derechos colectivos en la jurisprudencia de la Corte IDH y de la CIDH, véase: GaJARDO FALCón (2014a), pp. 145-171. 
especial relación que tienen los pueblos indígenas con su territorio ${ }^{10}$ y con los recursos naturales que allí se encuentran, fundamentales para el aseguramiento de sus formas de vida, alimentación y subsistencia ${ }^{11}$. Asimismo, se reitera la conexión del derecho humano a la propiedad colectiva indígena y los derechos culturales de los pueblos indígenas y sus integrantes ${ }^{12}$.

En cuanto a los aspectos novedosos, para la CIDH el caso lo es, primero, porque constituye una oportunidad para que la Corte IDH analice el alcance y contenido de la obligación de reparación de los pueblos indígenas cuando se ha determinado que no es posible la restitución de las tierras y territorios ocupados y usados ancestralmente ${ }^{13}$. Así, la Corte IDH "podrá analizar la forma en que el incumplimiento de esta obligación de reparación constituye una violación continuada del derecho a la propiedad colectiva de los pueblos indígenas que se ven despojados de sus tierras y territorios ancestrales y que, ante la imposibilidad de recuperarlos, el Estado no adopta medidas para permitir el ejercicio de su derecho a la propiedad"14.

La segunda cuestión novedosa para la CIDH, que se encuentra relacionada con la anterior, está dada por la relación intrínseca entre el cumplimiento efectivo y oportuno de las obligaciones de reconocimiento, titulación, demarcación y delimitación de las tierras y territorios de los pueblos indígenas, y la situación de vulnerabilidad y desprotección frente a actos de terceros con impactos profundos en los medios de subsistencia tradicional y en la vida social y cultural ${ }^{15}$.

A los puntos anteriores, agrego tres ítems que el presente caso coloca de relieve y que serán relevantes para la jurisprudencia del Sistema Interamericano de Derechos Humanos (en adelante "SIDH"). El primero, dice relación con la competencia ratione temporis ${ }^{16}$ y los aspectos procesales que se derivan de ello, en especial, con el requisito de agotamiento de recursos internos para que

10 Véase: Comisión Interamericana de Derechos Humanos (2012), párr. 193.

11 Ídem, párr. 194. Asimismo, véase: Clérico y AldaO (2011), pp. 157-198.

12 Véase: Comisión Interamericana de Derechos Humanos (2012), párr. 193.

13 Véase: Comisión Interamericana de Derechos Humanos (2013), p. 4.

14 Ibidem. Para un estudio amplio de las modalidades de las "reparaciones" que ha utilizado la Corte IDH, véase: NASH (2007), pp. 37-78.

15 Véase: Comisión Interamericana de Derechos Humanos (2013), p. 4.

16 Véase nota al pie número 6. 
el caso pueda ser conocido por la Corte IDH $^{17}$. Ello por cuanto, si bien, la CIDH establece que la controversia se debe al incumplimiento de las obligaciones estatales posteriores a la fecha de que el Estado otorgara competencia a la Corte IDH, los hechos basales que originan el presente caso se deben a acciones estatales ocurridas con anterioridad a ello. Por lo anterior, el presente caso es un excelente ejemplo de conflictos que tienen los Estados de América derivados de acciones cometidas antes de la suscripción de la $\mathrm{CADH}$ y de las cuales se ha generado una situación histórica de vulneración de los derechos humanos de los pueblos indígenas ${ }^{18}$.

El segundo está dado por el carácter colectivo del derecho de propiedad indígena. La jurisprudencia de la Corte IDH al respecto ha ido cambiando en la conceptualización de las características de lo colectivo del derecho de propiedad indígena, teniendo un punto de inflexión con la dictación de las sentencias del caso de la Comunidad Indígena Xákmok Kásek c. Paraguay (2010) ${ }^{19}$ y del

$17 \mathrm{Al}$ respecto, José Remotti señala que la: “(...) exigencia de agotar la jurisdicción interna antes de recurrir ante el sistema interamericano de protección de los derechos humanos no debe entenderse como una obligación de carácter absoluto, pues la propia Convención, y luego la jurisprudencia de la Corte, como veremos posteriormente al analizar las excepciones preliminares, han considerado que pueden darse circunstancias en las que ha de ser viable, legítimamente, que se pueda recurrir de forma directa ante la Comisión Interamericana”, véase: Rемотті (2004), pp. 126-127. Por su parte Cecilia Medina y Claudio Nash, sostienen que el agotamiento de recursos internos sólo puede operar como una excepción y, por ende, se requiere que el Estado la haya opuesto en el marco del proceso que se siguió ante la CIDH. Al respecto señalan: "De esta forma, es renunciable y será el Estado denunciado quien podrá invocarlo como excepción de admisibilidad en la etapa que corresponda ejercerla. No corresponde a la Comisión pronunciarse sobre el agotamiento de los recursos internos sin darle una oportunidad al Estado para que invoque esta causal de admisibilidad o la renuncie, tácita o expresamente (...) si el Estado no la ha deducido ante la Comisión en esa oportunidad, no podrá oponerla ante la Corte Interamericana. La Corte ha expresado que, al no haber alegado el Estado la excepción ante la Comisión”, véase: Medina y NASH (2011), p. 34. Por su parte, la jurisprudencia de la Corte IDH, sistemáticamente, ha señalado que si la excepción de agotamiento de los recursos internos no se opuso en el proceso ante la $\mathrm{CIDH}$ se entiende su renuncia tácita para el procedimiento posterior ante la Corte IDH. Al respecto, a modo ejemplar, véase: CORTE INTERAMERICANA DE DereChOS Humanos, 4 de septiembre de 1998, párr. 56. En el presente caso, en el Informe de Fondo en comento se constata que el Estado no ejerció la excepción de agotamiento de recursos internos [Comisión Interamericana de Derechos Humanos (2012), párrs. 32-41], por lo que veremos en el proceso ante la Corte IDH si la utiliza y, en definitiva, qué se resuelve al respecto.

18 Un ejemplo de ello, puede ser la situación del pueblo mapuche en Chile con respecto a las leyes dictadas durante la segunda mitad del siglo veinte y lo que se ha denominado el proceso de "usurpación" y "liquidación" de la comunidad mapuche. Al respecto, véase: NAVARrETE (2013).

19 Véase: Corte Interamericana de Derechos Humanos, 24 de agosto de 2010, párrs. 64-79. 
Pueblo Indígena Kichwa de Sarayaku c. Ecuador (2012) ${ }^{20}$, confluyendo con la posición que ha defendido la $\mathrm{CIDH}$ y anclando sus presupuestos en una concepción fuerte de la misma ${ }^{21}$.

Hasta las sentencias señaladas como punto de inflexión, la CIDH ha defendido ante la Corte IDH una concepción de la propiedad colectiva indígena, en la cual tanto la titularidad como el ejercicio corresponden al grupo en todo o en parte, la que he denominado: concepción fuerte de la propiedad colectiva indígena. Sin embargo, con una visión más restrictiva, la Corte IDH ha señalado que la propiedad indígena es un derecho colectivo, cuyos titulares son las personas individuales que conforman los pueblos indígenas o tribales, y su ejercicio se desenvuelve en sistemas de propiedad colectivos $^{22}$.

Con el presente caso, veremos si la tendencia que se ha ido construyendo en la jurisprudencia de la Corte IDH sigue en ese sentido o, en su defecto, la Corte IDH vuelve a sus concepciones previas sobre el entendimiento de lo colectivo de la propiedad indígena ${ }^{23}$.

El tercer aspecto y algo más general, tiene relación con la características del acuerdo entre el Estado de Panamá y los pueblos indígenas del caso para su reubicación en tierras diferentes a las que constituían su territorio ancestral y las posibilidades -o no- que tendrían los Estados para llegar a un acuerdo de este tipo, cuando la reubicación de los pueblos indígenas puede colocar en riesgo la subsistencia de los mismos ${ }^{24}$. Ello se encuentra conectado con lo que se ha denominado como derecho a la supervivencia cultural ${ }^{25}$ y del cual se deriva una larga y densa discusión entre liberales y comunitaristas ${ }^{26}$.

20 Véase: Corte Interamericana de Derechos Humanos, 27 de junio de 2012, párr. 231.

21 Véase: Gajardo Falcón (2014b), pp. 60-64. Para una justificación teórica de los derechos colectivos, véase: ToRBISCO (2006). Asimismo, revisando la posibilidad de conceptualizar derechos de grupo en el plano de la teoría del derecho, véase: Rodríguez AbasCal (2002), pp. 409-434.

$22 \mathrm{Al}$ respecto, véase: 1) Corte Interamericana de Derechos Humanos, 31 de agosto de 2001, párr. 149; 2) Corte Interamericana de Derechos Humanos, 17 de junio de 2005, párrs. 188-189; 3) Corte Interamericana de Derechos Humanos, 29 de marzo de 2006, párr. 210.

$23 \mathrm{Al}$ respecto, véase: GajARdo FALCÓN (2014a), pp. 156-160.

24 Véase: Yrigoyen (2011), pp. 103-146. Asimismo, véase: Arévalo (2014).

25 Véase: Anaya (2005), pp. 135-141. Asimismo, véase: Aguilar (2007), pp. 454-519.

26 Sobre la abundante literatura al respecto, destacamos la siguiente: TAYLOR (1994), pp. 25-73; KyMLICKA (1995); KyмLicKa (2001). 


\section{REFLEXIONES FINALES SOBRE EL DERECHO}

El nuevo caso que ha puesto la CIDH para conocimiento y fallo de la Corte IDH, es representativo de la tensión que existe entre los derechos humanos de los pueblos indígenas, en particular el derecho de propiedad colectiva indígena -con los vínculos y conexiones en otros derechos, ya anotados- y el modelo de desarrollo de los Estados de las Américas, basado en megaproyectos de inversión energéticos, mineros u otros, que generalmente se emplazan en los territorios ancestrales indígenas.

La tensión entre los Estados y pueblos indígenas de las américas por la ocupación del territorio que los últimos han poseído ancestralmente, ha aumentado durante la última década ${ }^{27}$, dando cuenta de un debate profundo que existe en la sociedad latinoamericana, que consiste en la prevalencia del interés general (conformado principalmente por una sociedad no indígena y un modelo de desarrollo capitalista, basado en la explotación de recursos naturales y ocupación del territorio indígena) y el respeto de los derechos de los pueblos indígenas, a quienes en aras del "desarrollo" se les priva de su hábitat ancestral y de sus modos de vida tradicionales ${ }^{28}$.

La tensión identificada se encuentra presente en todos los países de América Latina y el Caribe, incluso en aquellos que cuentan con un amplio reconocimiento de los derechos de los pueblos indígenas y presencia de indígenas en los órganos de poder del Estado. Un caso que ejemplifica lo anterior, es el del Estado Plurinacional de Bolivia. Álvaro García Linera, actual vice-presidente del Estado, señala que una de las principales tensiones que tiene el proceso boliviano es entre la “(...) necesidad y voluntad de industrialización de las materias primas, y la

27 Algunos ejemplos recientes son: 1) Las protestas del año 2011 realizadas por los pueblos indígenas en Bolivia que se oponían a la construcción de una carretera que pasaría por el Parque Isiboro Sécure (TIPNIS) para facilitar el comercio con Brasil; 2) Los conflictos que se viven permanentemente entre las empresas madereras y el pueblo mapuche en el sur de Chile; 3) Los conflictos que se han suscitado durante los últimos años entre el gobierno de Brasil y los pueblos indígenas amazónicos, por la construcción de la represa de Belo Monte. Sobre el caso boliviano y una revisión crítica de sus políticas recientes en materia indígena, véase: AylWin (2013), pp. 168-200.

28 Véase: Torrecuadrada (2013), pp. 552-554. Para Rowlands, lo que se encuentra detrás de la tensión identificada son las diferentes concepciones y relaciones con la naturaleza que hay en juego. Al respecto, véase: Rowlands (2013), pp. 68-98. 
necesidad imprescindible del Vivir Bien entendido como la práctica dialogante y mutuamente vivificante con la naturaleza que nos rodea" 29 .

Así las cosas, el presente caso será relevante para el fortalecimiento -o no- de las líneas jurisprudenciales que ha tenido en las últimas dos décadas el SIDH y para el desarrollo de nuevas aristas de las mismas, con ocasión de los aspectos "novedosos" que contiene el caso.

En la medida que los Estados cumplan los parámetros jurisprudenciales establecidos por la Corte IDH, la perspectiva indígena irá incorporándose paulatinamente en el funcionamiento interno de las instituciones del Estado, permeando la actividad y gestión de la administración pública y generando, posiblemente, un cuestionamiento a la relación que hasta ahora han tenido los Estados de América con los pueblos indígenas y su territorio.

\section{BibLIOGRAFÍA CITADA}

Aguilar, Gonzalo (2007): Dinámica internacional de la cuestión indígena (Santiago de Chile, Librotecnia).

AnAYA, James (2005): Los pueblos indígenas en el Derecho Internacional (Traducc. Luis Piñero Arroyo, Madrid, Trotta).

Antokowiak, Thomas (2014): "Rights, Resources, and Rhetoric: Indigenous Peoples and the Inter-American Court”, en U. Pa. J. Int'l L (No 35), pp. 113187.

Arévalo, Amelia (2014): El derecho a la consulta previa de los pueblos indígenas en el Derecho Internacional (San Sebastián, Cuadernos Deusto de Derechos). Aylwin, José (2013): "Bolivia: Desarrollo o buen vivir. El caso del Tipnis”, en Marti i Puig, Salvador; Wright, Claire; Aylwin, José; Yáñez, Nancy (eds.), Entre el Desarrollo y el Buen Vivir (Madrid, Catarata), pp. 168-200.

ClériCo, Laura y AldaO, Martín (2011): "La igualdad como redistribución y reconocimiento: Derechos de los Pueblos Indígenas y Corte Interamericana de Derechos Humanos", en Estudios Constitucionales (Año 9, No 1), pp. 157-198.

Comisión Interamericana de Derechos Humanos (2013). "Nota de remisión del caso No 12.354 a la Corte IDH" [fecha de consulta: 4 de septiembre de 2014], [Disponible en: http://www.oas.org/es/cidh/indigenas/decisiones/cidh.asp].

29 García Linera (2011), pp. 62-63. 
Comisión Interamericana de Derechos Humanos (2012): "Informe de Fondo No 125/12", [fecha de consulta: 4 de septiembre de 2014], [Disponible en: http://www.oas.org/es/cidh/indigenas/decisiones/cidh.asp].

Comisión Interamericana de Derechos Humanos (2009): "Derechos de los Pueblos Indígenas y Tribales sobre sus tierras ancestrales y recursos naturales". [fecha de consulta: 4 de septiembre de 2014], [Disponible en: http://www. oas.org/es/cidh/indigenas/docs/pdf/Tierras-Ancestrales.ESP.pdf].

Comisión Interamericana de Derechos Humanos (1990): "Informe de Admisibilidad No 74/90" [fecha de consulta: 29 de septiembre de 2014], [Disponible en: http://www.cidh.oas.org/annualrep/90.91sp/Argentina9850.htm].

Espejo, Nicolás y LeIva, Carla (2012): Digesto de Jurisprudencia de la Corte Interamericana de Derechos Humanos (Santiago de Chile, AbeladoPerrot).

Gajardo Falcón, Jaime (2014a): "Derechos de los grupos en el Sistema Interamericano de Protección de los Derechos Humanos", en Hierro, Liborio (coord.), Autonomía individual frente a autonomía colectiva. Derechos en conflicto (Madrid, Marcial Pons), pp. 145-171.

Gajardo Falcón, Jaime (2014b): "Nuevas perspectivas de los derechos de los grupos a partir del análisis de la jurisprudencia de la Corte Interamericana de Derechos Humanos sobre los Derechos de los Pueblos Indígenas", en Revista Tribuna Internacional (No 5), pp. 43-64.

García Linera, Álvaro (2011): Las Tensiones creativas de la revolución (La Paz, Vicepresidencia del Estado Plurinacional).

Kymlicka, Will (1995): Multicultural Citizenship (Oxford, Oxford University Press).

Kyмlicka, Will (2001): Politics in the vernacular (Oxford, Oxford University Press). Medina, Cecilia y Nash, Claudio (2011): Sistema Interamericano de Derechos Humanos: Introducción a sus Mecanismos de Protección (Santiago de Chile, Centro de Derechos Humanos, Universidad de Chile).

NaSH, Claudio (2007): Las reparaciones ante la Corte Interamericana de Derechos Humanos (Santiago de Chile, Centro de Derechos Humanos, Universidad de Chile).

Nash, Claudio (2004): "Los derechos humanos de los indígenas, en la jurisprudencia de la Corte Interamericana de Derechos Humanos", en AYLWIN, José (ed.), Derechos Humanos y Pueblos Indígenas: Tendencias Internacionales y Contexto Chileno (Temuco, Instituto de Estudios Indígenas, Universidad de la Frontera), pp. 29-43. 
NaVArRete, Manuel (2013): Constitucionalización indígena: Variaciones jurídicas y metajurídicas (Santiago de Chile, Librotecnia).

RemotтI, José (2004): La Corte Interamericana de Derechos Humanos. Estructura, funcionamiento y jurisprudencia (Lima, Idemsa).

Rodríguez Abascal, Luis (2002): "El debate sobre los derechos de grupo", en Díaz, Elías y Colomer, Juan (eds.), Estado, Justicia y Derechos (Madrid, Alianza Editorial), pp. 409-434.

ROWLANDS, Jorge (2013): "Estados latinoamericanos frente a la consulta indígena: tensión cultural en la implementación de los derechos territoriales", en MARTI i Puig, Salvador; Wright, Claire; Aylwin, José; Yáñez, Nancy (eds.), Entre el Desarrollo y el Buen Vivir (Madrid, Catarata), pp. 68-98.

TAYLor, Charles (1994): “The Politics of Recognition”, en Gutmann, Amy (ed.), Multiculturalism (Princeton, Princeton University Press), pp. 25-73.

Torbisco, Neus (2006): Group Rights as Human Rights. A Liberal Approach to Multiculturalism (Barcelona, Springer).

Torrecuadrada, Soledad (2013): “Identidad indígena”, en Anuario de la Facultad de Derecho de la Universidad Autónoma de Madrid (No 17), pp. 552-554.

YRIGOYEN, Raquel (2011): "El derecho a la libre determinación del desarrollo. Participación, consulta y consentimiento", en Aparicio, Marco (ed.), Los derechos de los pueblos indigenas a los recursos naturales y al territorio (Barcelona, Icaria), pp. 103-146

\section{JURISPRUDENCIA CITADA}

Castillo Petruzzi y otros con Perú (1998): Corte Interamericana de Derechos Humanos, 4 de septiembre de 1998, en Serie C No 41.

Comunidad Indigena Sawhoyamaxa con Paraguay (2006): Corte Interamericana de Derechos Humanos, 29 de marzo de 2006, en Serie C No 146.

Comunidad Indigena Xákmok Kásek con Paraguay (2010): Corte Interamericana de Derechos Humanos, 24 de agosto de 2010, en Serie C No 214.

Comunidad Indigena Yakye Axa con Paraguay (2005): Corte Interamericana de Derechos Humanos, 17 de junio de 2005, en Serie C No 125.

Grande con Argentina (2011): Corte Interamericana de Derechos Humanos, 31 de agosto de 2011, en Serie C No 231.

Mayagna (Sumo) Awas Tingni con Nicaragua (2001): Corte Interamericana de Derechos Humanos, 31 de agosto de 2001, en Serie C No 79. 
Pueblo Indigena Kichwa de Sarayaku con Ecuador (2012): Corte Interamericana de Derechos Humanos, 27 de junio de 2012, en Serie C No 245.

Radilla Pacheco con México (2009): Corte Interamericana de Derechos Humanos, 23 de noviembre de 2009, en Serie C No 209. 